\title{
Binding Properties of Cucurbit[7]uril to Neutral and Protonated Amino Acids: A Computational Study
}

\author{
Fenfen $\mathrm{Ma}^{1}$, Xiaoyan Zheng ${ }^{1}$, Jing Xie ${ }^{1}$, and Ze-Sheng $\mathrm{Li}^{1}$ \\ ${ }^{1}$ Beijing Institute of Technology
}

June 16, 2020

\begin{abstract}
We systematically investigate the binding nature of $\mathrm{CB}[7]$ towards 20 amino acids in both neutral (AAs) and protonated $\left(\mathrm{AAs}^{+}\right)$states by quantum chemistry methods. The result indicates molecular recognition process are enthalpy-driven. Among AAs, Arg and Asn shows the largest binding strength to $\mathrm{CB}[7]$, and for $\mathrm{AAs}^{+}, \mathrm{Gln}^{+}$and Asn ${ }^{+}$bind to $\mathrm{CB}[7]$ the strongest. The binding strength of protonated $\mathrm{CB}[7] / \mathrm{AA}^{+}$is much stronger than that of neutral $\mathrm{CB}[7] / \mathrm{AA}$ counterpart, due to the introduction of ion-dipole interaction and the increase number and strength of hydrogen bonds. Energy decomposition analysis (EDA) indicates that electrostatic interactions play major roles in both $\mathrm{CB}[7] / \mathrm{AAs}$ and $\mathrm{CB}[7] / \mathrm{AAs}^{+}$complexes. Moreover, we analyzed the dependence of binding strength on single AA volume and dipole moment. This study is benefit for providing valuable information in predicting the recognition sites for sequence-based peptide or protein by CB[7] and rationally designing synthetic host molecule for specific peptide or protein recognition.
\end{abstract}

\section{Hosted file}

Manuscript.pdf available at https://authorea.com/users/333853/articles/459923-bindingproperties-of-cucurbit-7-uril-to-neutral-and-protonated-amino-acids-a-computationalstudy 